\title{
Aspirin plus ticagrelor or clopidogrel on graft patency one year after coronary bypass grafting: a single-center, randomized, controlled trial
}

\author{
Yangfeng Tang", Xinli Fan", Boyao Zhang, Jiajun Zhang, Qin Xue, Zhiyun Xu, Lin Han \\ Department of Cardiothoracic Surgery, Changhai Hospital, The Second Military Medical University, Shanghai, China \\ Contributions: (I) Conception and design: Y Tang, Z Xu, L Han; (II) Administrative support: Z Xu, L Han; (III) Provision of study materials or \\ patients: Z Xu, L Han; (IV) Collection and assembly of data: Y Tang, X Fan, B Zhang, J Zhang, Q Xue; (V) Data analysis and interpretation: Y Tang, \\ Z Xu, L Han; (VI) Manuscript writing: All authors; (VII) Final approval of manuscript: All authors. \\ \#These authors contributed equally to this work. \\ Correspondence to: Dr. Yangfeng Tang, MD; Dr. Lin Han, MD. Department of Cardiothoracic Surgery, Changhai Hospital, The Second Military \\ Medical University, 168 Changhai Road, Shanghai 200433, China. Email: tangyfch265@163.com; sh_hanlin@163.com.
}

\begin{abstract}
Background: Dual antiplatelet therapy (DAPT) improves early post-operative graft patency, but the optimal DAPT strategy for the patients after coronary artery bypass grafting (CABG) has not been confirmed. We sought to evaluate the effect of aspirin plus ticagrelor versus aspirin plus clopidogrel on saphenous vein graft (SVG) patency within 1 year after CABG.

Methods: Between October 2017 and December 2018, 147 consecutive patients undergoing elective CABG at Changhai Hospital were randomized into two groups: group AT, receiving aspirin $100 \mathrm{mg} / \mathrm{d}$ plus ticagrelor $2 \times 90 \mathrm{mg} / \mathrm{d}$; group AC, receiving aspirin $100 \mathrm{mg} / \mathrm{d}$ plus clopidogrel $75 \mathrm{mg} / \mathrm{d}$. Both DAPTs should be administered within $24 \mathrm{~h}$ when clinical stability was ensured. 64-multislice computed tomography angiography (MSCTA) was used to assess the graft patency at 12 months after CABG.CYP2C19 gene variants were measured to assess the clopidogrel efficacy on graft patency.
\end{abstract}

Results: Among the 147 participants who completed the study, one (0.7\%) patient from the AC group died at 5 weeks after surgery due to severe infection. All other patients were treated with DAPT for 12 months and underwent 64-MSCTA according to schedule. There were no significant differences in pre-operative characteristics and intraoperative transit-time flow measurement findings between the two groups. Besides, no significant differences in the incidence of major adverse cardiac events (MACEs) and major bleeding were observed. A 64-MSCTA showed that SVG patency was 91.0\% (141 of 155) in the AT group and 89.9\% (161 of 179) in the AC group ( $\mathrm{P}=0.751)$. No significant associations were found between different CYP2C19 genotypes and SVG patency $(\mathrm{P}>0.05)$.

Conclusions: Either aspirin plus ticagrelor or aspirin plus clopidogrel can maintain a fairly high graft patency rate in the early phase after CABG, regardless of CYP2C19 genotypes.

Keywords: Antiplatelet therapy; coronary artery bypass grafting (CABG); clopidogrel; ticagrelor; graft patency

Submitted Nov 30, 2020. Accepted for publication Jan 29, 2021.

doi: $10.21037 /$ jtd-20-3407

View this article at: http://dx.doi.org/10.21037/jtd-20-3407

\section{Introduction}

Coronary artery bypass grafting (CABG) remains the "gold standard" treatment for coronary artery revascularization in patients with left main or complex multivessel disease, left ventricular dysfunction, and diabetes (1). Saphenous veins are still the most frequently used conduits for CABG in the United States and China (2). Yet, unlike arterial graft that has a high long-term patency rate, the patency of saphenous 
vein graft (SVG), which is associated with worse long-term outcomes patency, is only $80 \%$ to $85 \%$ at 1 year (3).

Among many factors that contribute to SVG failure, platelet activation and thrombosis have been identified as a major risk factor for early SVG stenosis. Antiplatelet therapy with aspirin, which can improve vein graft patency and reduce major adverse cardiac event (MACE) rates, has been recommended after CABG. Despite the use of aspirin, adverse cardiovascular event rates in the first year after CABG exceed 10\% (4). Dual antiplatelet therapy $(\mathrm{DAPT})$ with aspirin + a $\mathrm{P} 2 \mathrm{Y}_{12}$ receptor antagonist (clopidogrel) has shown to enhance antiplatelet activity and improve outcomes in patients after CABG $(5,6)$. Yet, some individuals may be less responsive to clopidogrel. This antiplatelet medication is activated by several enzymes, including CYP2C19; genetic variation in CYP2C19 may alter enzyme activity (7).

Ticagrelor, as a promising new antiplatelet drug that is reversibly binding and direct-acting $\mathrm{P} 2 \mathrm{Y}_{12}$ receptor antagonist, has shown beneficial results compared with clopidogrel in patients with acute coronary syndromes (ACS) (8). Several studies have suggested that ticagrelor is superior to aspirin in maintaining the patency of SVG and preventing major cardiovascular events within 1 year after CABG $(9,10)$. However, the optimal DAPT strategy for the patients after CABG has not yet been established.

The aim of this study was to compare the effect of aspirin+ticagrelor or aspirin+clopidogrel on SVG patency and incidence of cardiovascular events within 1 year after CABG.

We present the following article in accordance with the CONSORT reporting checklist (available at http://dx.doi. org/10.21037/jtd-20-3407).

\section{Methods}

\section{Patients}

One hundred forty-seven consecutive patients undergoing elective CABG at Changhai Hospital between October 2017 and December 2018 were enrolled in the study (Figure 1). All surgeries were conducted by the same surgeon (Prof. Han). The study was conducted in accordance with the Declaration of Helsinki (as revised in 2013). All data were collected from the Division of Cardiothoracic Surgery under the permission of the Institutional Review Board of Changhai Hospital (Number: CHCS052017). Informed consent was obtained from all patients.
Exclusion criteria were: patients with an abnormal quantity of platelets before operation $\left(<100 \times 10^{9} / \mathrm{L}\right.$ or $>300 \times 10^{9} / \mathrm{L}$ ); urgent $\mathrm{CABG}$; previous $\mathrm{CABG}$ or other cardiac surgery; concomitant valve or other cardiac surgery; single vessel disease; left ventricular ejection fraction $<30 \%$ on preoperative ultrasound; infusion of fresh platelets during or after $\mathrm{CABG}$; the need for perioperative warfarin; an active gastroduodenal ulcer or postoperative gastrointestinal bleeding; postoperative low cardiac output syndrome; perioperative myocardial infarction.

Patients with CABG surgery were randomized into two groups: AT group, receiving aspirin $100 \mathrm{mg} / \mathrm{d}$ plus ticagrelor $2 \times 90 \mathrm{mg} / \mathrm{d}$; AC group, receiving aspirin $100 \mathrm{mg} / \mathrm{d}$ plus clopidogrel $75 \mathrm{mg} / \mathrm{d}$. Both antiplatelet therapies. All medications were administered within $24 \mathrm{~h}$ when clinical stability was ensured. All patients received DAPT for 12 months after CABG.

\section{Endpoints}

The incidence of graft occlusion at one year after bypass surgery was assessed by multislice computed tomography angiography (MSCTA), which was the primary endpoint. The occurrence of major adverse cardiac events (MACE) was the secondary endpoint. MACE was recognized if one of the following occurred during treatment: cardiovascular death, nonfatal myocardial infarction, or nonfatal stroke.

\section{CYP2C19 genotyping}

CYP2C19 genotype was measured in all study patients. A peripheral venous blood sample was obtained before the operation. Genomic DNA was extracted from whole blood using the DNA Extractor kit (Tiangen, Beijing, China). Polymerase chain reaction-restriction fragment length polymorphisms for CYP2C19*2 $(681 \mathrm{G}>\mathrm{A})$ and $\mathrm{CYP} 2 \mathrm{C} 19^{*} 3$ $(636 \mathrm{G}>\mathrm{A})$ were performed as previously described. CYP2C19 genotypes were classified into three phenotypes: (I) extensive metabolizer (EM) carrying normal function alleles (CYP2C19*1/*1); (II) intermediate metabolizer (IM) carrying one loss-of-function allele $\left({ }^{*} 1 /{ }^{*} 2,{ }^{*} 1 /{ }^{*} 3\right)$; (III) poor metabolizer $(\mathrm{PM})$ carrying two loss-of-function alleles $\left({ }^{*} 2 / * 2,{ }^{*} 2 / * 3,{ }^{*} 3 / * 3\right)$.

Sample size: according to previous studies, aspirin plus Ticagrelor has a venous graft occlusion rate of $13 \%$ one year after surgery. As for aspirin plus Clopidogrel, the rate is $3.7 \%$. We found that a $5 \%$ difference between 2 arms can 


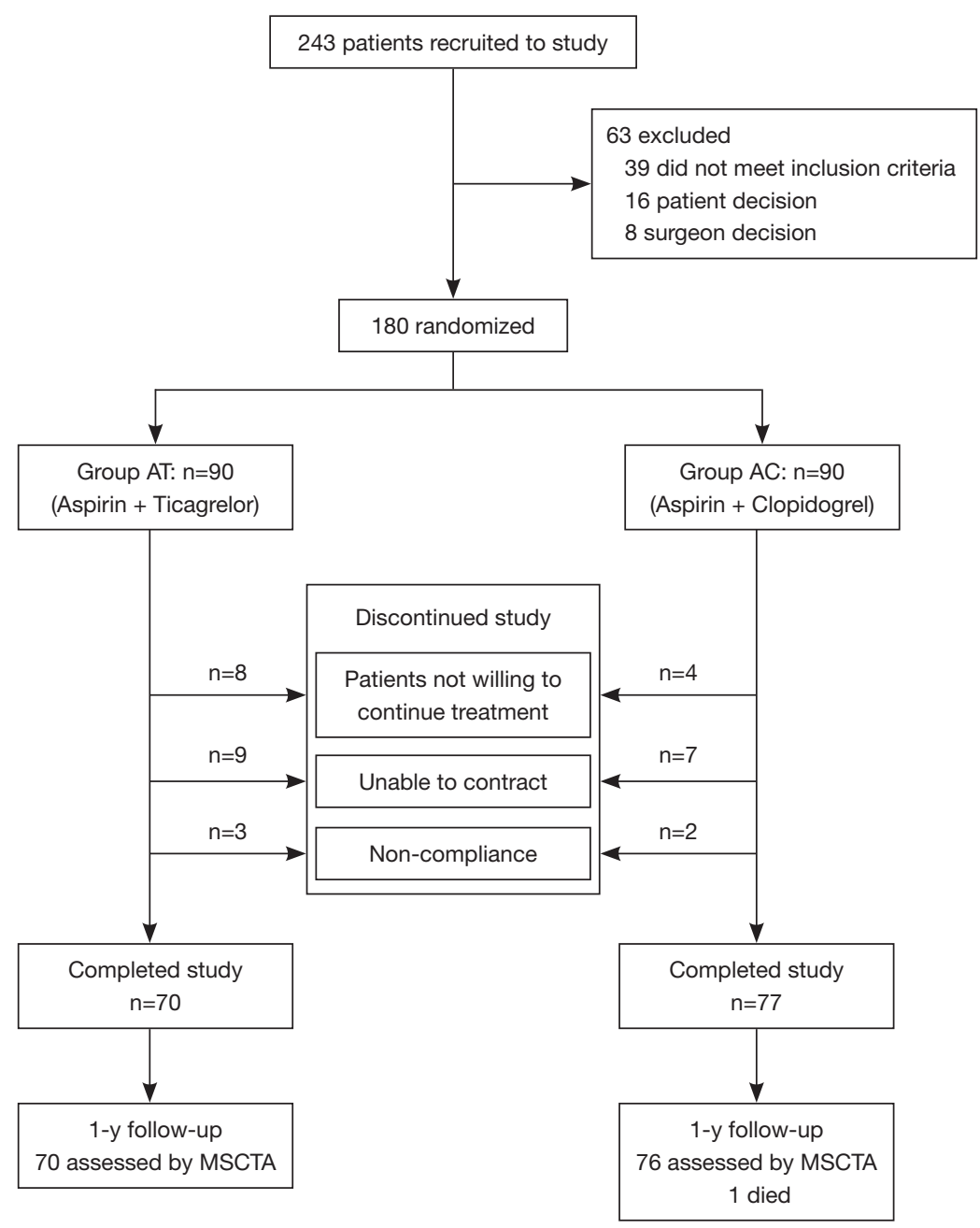

Figure 1 Flow chart of the study. MSCTA, multislice computed tomography angiography.

be reliably detected under a power of $80 \%$, if we have 170 venous grafts in each arm (significance level $=0.05$ ).

\section{Surgical procedures}

All patients underwent either off-pump or on-pump CABG that was performed based on anatomic and clinical findings by a single experienced surgeon. The left internal mammary artery (LIMA) was routinely anastomosed to the left anterior descending artery, and SVG was anastomosed to other target vessels with aorto-coronary or sequential bypass. During the operation, mean flow values $(>10 \mathrm{~mL} / \mathrm{min})$ were detected with transit-time flow measurement (Medistim Oslo Norway) to confirm the graft patency.

\section{Graft patency by 64-MSCTA}

A 64-MSCTA was used to assess the graft patency at 12 months after CABG in all follow-up patients. Two radiologists and a cardiac surgeon independently reviewed the results of MSCTA. Each graft was classified as patent (visible flow, not only at the anastomotic site but also in the main body of the graft), or occluded (a conduit was not filled with contrast at all). Graft patency was defined according to FitzGibbon criteria. Contrast filling of the grafts, anastomoses, and coronary arteries beyond the graft were considered in each assessment. FitzGibbon grade A indicates that the graft is patent with $\leq 50 \%$ stenosis; FitzGibbon grade B indicates that the extent of graft 
Table 1 Preoperative clinical characteristics in AT and AC groups

\begin{tabular}{|c|c|c|c|}
\hline Characteristic & AT group $(n=70)$ & $A C$ group $(n=77)$ & $P$ value \\
\hline Male, n (\%) & $42(60.0)$ & $47(61.0)$ & 0.89 \\
\hline $\mathrm{BMI}\left(\mathrm{kg} / \mathrm{m}^{2}\right)$ & $25.4 \pm 2.9$ & $25.5 \pm 2.8$ & 0.62 \\
\hline Diabetes, n (\%) & $23(32.9)$ & $25(32.5)$ & 0.96 \\
\hline Hyperlipidemia, n (\%) & $27(38.6)$ & $31(40.3)$ & 0.96 \\
\hline History of smoking, n (\%) & $28(40.0)$ & $39(50.6)$ & 0.25 \\
\hline Previous CVA, n (\%) & $5(7.1)$ & $5(6.5)$ & 0.87 \\
\hline Previous PCI, n (\%) & $5(7.1)$ & $11(14.3)$ & 0.26 \\
\hline ST segment elevation MI & $13(54.2)$ & $12(44.4)$ & \\
\hline Carotid artery stenosis, n (\%) & $9(12.9)$ & $15(19.5)$ & 0.38 \\
\hline Pre-operative LVEF (\%) & $59.5 \pm 7.8$ & $61.8 \pm 7.6$ & 0.31 \\
\hline Pre-operative LVDD (mm) & $49.4 \pm 7.3$ & $48.6 \pm 7.6$ & 0.41 \\
\hline
\end{tabular}

BMI, body mass index; CVA, cerebrovascular accident; PCI, percutaneous coronary intervention; MI, myocardial infarction; LVEF, left ventricular ejection fraction; LVDD, left ventricular diastolic dimension.

stenosis is $>50 \%$ but not occluded; and FitzGibbon grade O indicates total occlusion of the graft without contrast filling.

\section{Statistical analysis}

Clinical baseline characteristics and postoperative outcomes were statistically compared using SPSS version 17.0 software (SPSS Inc, Chicago, IL). Continuous variables with non-normal distribution were presented as median (IQR), while means \pm SD and percentage were used for categorical variables. The Student $t$-test and chi-square test were used to analyze continuous and categorical variables, respectively. $\chi^{2}$ test was used to compare numeration data. A $\mathrm{P}$ value $<0.05$ was considered to be statistically significant.

\section{Results}

One hundred forty-seven consecutive patients undergoing elective CABG were enrolled, including 70 patients in the AT group and 77 in the AC group. No difference in age, gender, body mass index, history of smoking and hypertension, previous cerebrovascular accident, diabetes, hyperlipidemia, previous myocardial infarction, and previous percutaneous coronary intervention were found between groups (Table 1). In addition, no difference in graft characteristics (including distal anastomosis, graft type, number of grafts) and intraoperative transit-time flow measurement findings were found between AT and AC group (Table 2).

Among the 147 participants, $1(0.7 \%)$ patient in the AC group died 5 weeks after CABG surgery, due to severe pulmonary infection. All other patients were treated with DAPT for 12 months and underwent 64-MSCTA according to schedule.

A total of 3 MACEs were observed during 1 year of follow-up post-CABG, including $2(2.9 \%)$ in the AT group, and $1(1.3 \%)$ in the AC group $(\mathrm{P}=0.505)$. The incidence of recurrent angina was similar in patients treated with aspirin+ticagrelor (4.3\%), and those treated with aspirin+clopidogrel (5.2\%). There were no significant differences in the incidence of major bleeding and dyspnea during the follow-up time (Table 3).

The patency was examined in 477 grafts (LIMA, $n=143$; SVG, $n=334)$ of 146 patients. Overall, $34(7.1 \%)$ out of 477 grafts were classified as occluded; $15(6.7 \%)$ in the AT group and $19(7.5 \%)$ in the AC group $(\mathrm{P}=0.730)$. LIAM 
patency $(98.6 \%)$ was satisfied in two groups. SVG patency was $91.0 \%$ (141 of 155$)$ in the AT group and $89.9 \%$ (161 of $179)$ in the AC group $(\mathrm{P}=0.751)$. There were no significant differences in graft patency between the two groups at 1 year after CABG (Table 4). Additionally, in the multivariate

Table 2 Operative data in AT and AC groups

\begin{tabular}{lccc}
\hline Variables & $\begin{array}{c}\text { AT group } \\
(\mathrm{n}=70)\end{array}$ & $\begin{array}{c}\text { AC group } \\
(\mathrm{n}=77)\end{array}$ & P value \\
\hline Grafts number & 224 & 256 & - \\
Grafts/patient & $3.2(224 / 70)$ & $3.3(256 / 77)$ & - \\
Graft type & & & \\
LIMA & 69 & 75 & 0.71 \\
SVG & 155 & 181 & 0.71 \\
Sequential bypass & 19 & 18 & 0.55 \\
Flow of LIMA (mL/min) & $22.8 \pm 15.1$ & $23.7 \pm 16.7$ & 0.91 \\
Flow of SVG (mL/min) & $37.2 \pm 21.4$ & $36.9 \pm 23.5$ & 0.16 \\
OPCAB & $21(30.0 \%)$ & $24(31.2 \%)$ & 0.87 \\
\hline
\end{tabular}

LIMA, left anterior descending artery; SVG, saphenous vein graft; OPCAB, off-pump coronary artery bypass graft. analysis, mean graft flow was the strong predictor of higher venous graft patency (odds ratio 1.03, 95\% CI, 1.01-1.09, $\mathrm{P}=0.03$ ) (Table 5).

\section{Graft patency among different CYP2C19 phenotype groups}

The distribution of CYP2C19 genotype was $32.7 \%$, $48.9 \%, 4.1 \%, 11.6 \%$, and $2.7 \%$ in ${ }^{*} 1 /{ }^{*} 1,{ }^{*} 1 /{ }^{*} 2,{ }^{*} 1 /{ }^{*} 3$, $* 2 / * 2$, and ${ }^{*} 2 / * 3$, respectively. Patients were divided into three phenotypes: (I) EM, patients carrying normal function alleles $\left(\mathrm{CYP} 2 \mathrm{C} 19^{*} 1 /{ }^{*} 1\right)$; (II) IM, patients carrying one loss-of-function allele $\left(\mathrm{CYP} 2 \mathrm{C} 19^{*} 1 /{ }^{*} 2,{ }^{*} 1 /{ }^{*} 3\right)$; (III) PM, patients carrying two loss-of-function alleles (CYP2C19*2/*2,*2/*3,*3/*3). The distribution of the CYP2C19 phenotype was $32.6 \%, 53.1 \%$, and $14.3 \%$ in EM, IM, and PM, respectively (Table 6). The incidence of SVG closure within 1 year after CABG surgery was not significant among the EM, IM, and PM groups in patients receiving aspirin plus ticagrelor antiplatelet treatment (7.5\%, 9.3\%, and $11.1 \%$ in EM, IM, and PM, respectively; $\mathrm{P}=0.864)$. Interestingly, there were also no significant differences in the incidence of SVG closure among different CYP2C19 genotype groups in patients with aspirin plus

Table 3 Major adverse cardiovascular events, bleeding episodes, and other events in AT and AC groups

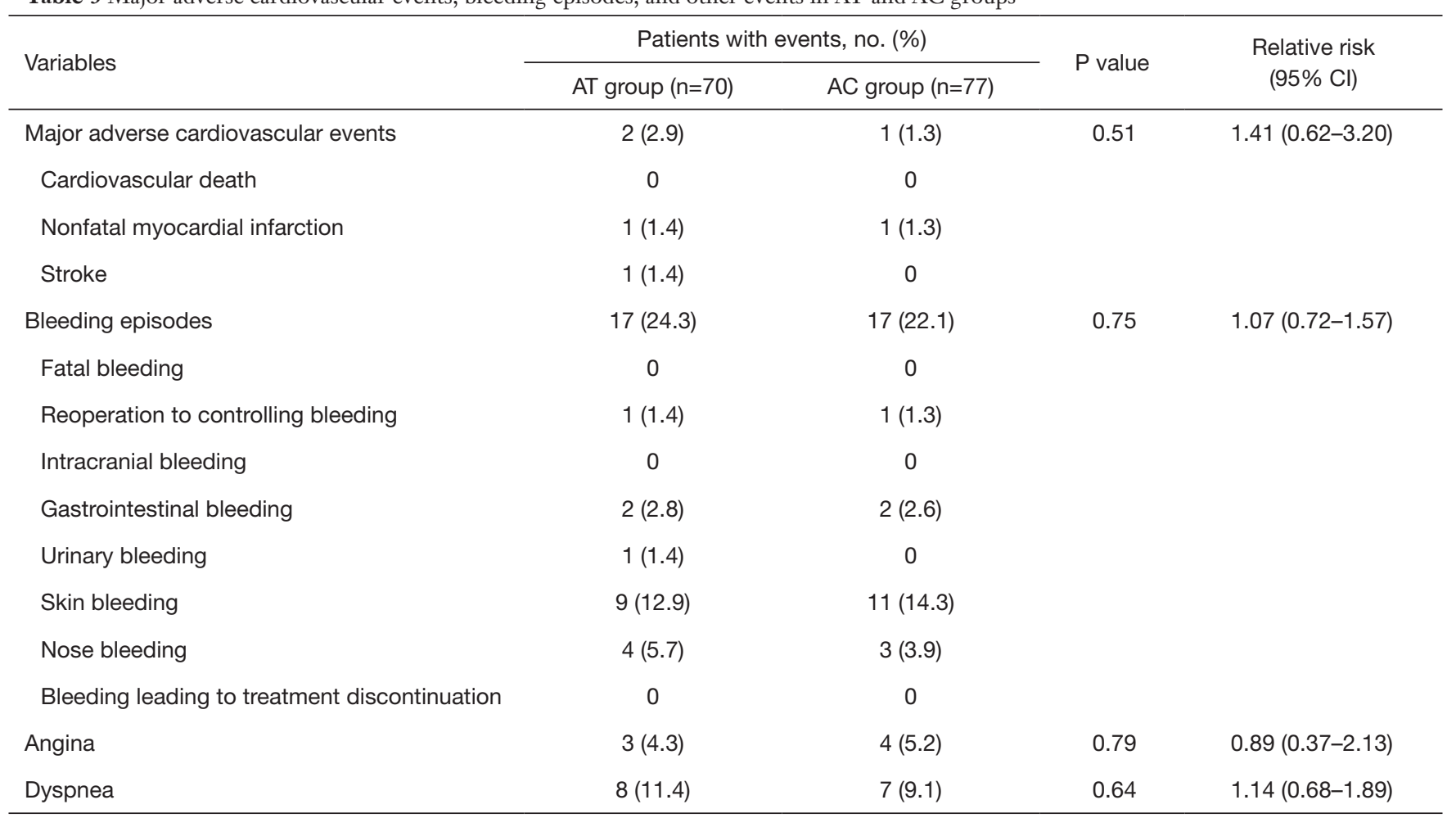


Table 4 Prevalence of graft occlusion in AT and AC groups

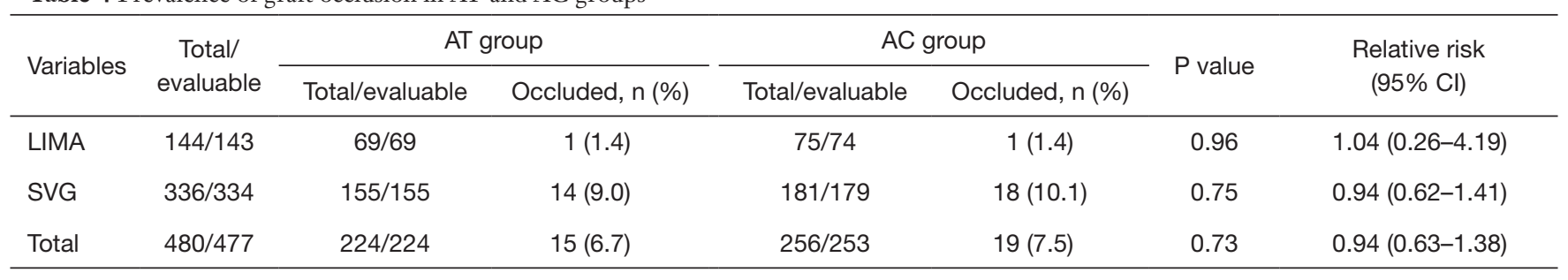

LIMA, left internal mammary artery, SVG, saphenous vein graft.

Table 5 Multivariate analysis of relative risk factors for venous graft patency at 1 year after CABG surgery

\begin{tabular}{|c|c|c|c|}
\hline Risk factor & Odds ratio & $95 \% \mathrm{Cl}$ & $P$ value \\
\hline Age & 1.03 & $0.61-1.17$ & 0.21 \\
\hline BMI & 1.02 & $0.99-1.14$ & 0.52 \\
\hline Mean graft flow & 1.03 & $1.01-1.09$ & 0.03 \\
\hline \multicolumn{4}{|l|}{ Sex } \\
\hline Male & Reference & & \\
\hline Female & 0.63 & $0.19-1.82$ & 0.41 \\
\hline \multicolumn{4}{|l|}{ Diabetes } \\
\hline Yes & Reference & & \\
\hline No & 0.93 & $0.29-1.92$ & 0.38 \\
\hline \multicolumn{4}{|l|}{ History of smoking } \\
\hline Yes & Reference & & \\
\hline No & 1.55 & $0.54-2.92$ & 0.85 \\
\hline \multicolumn{4}{|l|}{ Hyperlipidemia } \\
\hline Yes & Reference & & \\
\hline No & 1.13 & $0.69-2.42$ & 0.73 \\
\hline \multicolumn{4}{|l|}{ CABG procedure } \\
\hline On-pump & Reference & & \\
\hline Off-pump & 1.07 & $0.49-2.46$ & 0.81 \\
\hline \multicolumn{4}{|l|}{$\begin{array}{l}\text { Sequential } \\
\text { anastomosis }\end{array}$} \\
\hline Yes & Reference & & \\
\hline No & 0.86 & $0.24-2.81$ & 0.77 \\
\hline \multicolumn{4}{|l|}{ Antiplatelet therapy } \\
\hline Aspirin + ticagrelor & Reference & & \\
\hline Aspirin + clopidogrel & 1.55 & $0.64-3.66$ & 0.73 \\
\hline
\end{tabular}

clopidogrel antiplatelet treatment $(9.2 \%, 8.6 \%$, and $9.5 \%$ in $\mathrm{EM}, \mathrm{IM}$, and $\mathrm{PM}$, respectively; $\mathrm{P}=0.986$ ). Furthermore, compared with aspirin plus ticagrelor, aspirin plus clopidogrel has similar effectiveness in maintaining the patency of SVG, regardless of CYP2C19 genotypes (Table 7).

\section{Discussion}

Despite the undoubted success of CABG, early graft failure occurs in approximately $18 \%$ of cases. Antiplatelet therapy with aspirin is recommended for patients undergoing CABG since it may improve vein graft patency and reduce the MACE rate. However, even with standard aspirin therapy, a significant number of patients show resistance to aspirin, which results in increased risk for developing adverse cardiovascular events during the first year after CABG (4).

Clopidogrel is a prodrug that is metabolized by cytochrome P450 and can inhibit the diphosphateinduced platelet aggregation, selectively depress platelet cycloxygenase-1, and interrupt the formation of thromboxane A2. Compared with aspirin alone, a combination of clopidogrel and aspirin can lead to superior potent synergistic antithrombotic effects, and can more effectively prevent graft failure and cardiovascular events after CABG $(5,6)$. Despite the overall benefit, some individuals may be less responsive to clopidogrel (7).

Ticagrelor is a promising new antiplatelet drug with higher efficiency compared with clopidogrel in patients with acute coronary syndrome (ACS) (8). Several studies have proved that ticagrelor is superior to aspirin for maintaining the patency of SVG and the prevention of major cardiovascular events within 1 year after CABG $(9,10)$. Yet, the optimal DAPT strategy for the patients after CABG has not been established. To the best of our knowledge, this is the first study that compared the effect of aspirin+ticagrelor 
Table 6 Distribution of CYP2C19 genotype and phenotype in AT and AC groups

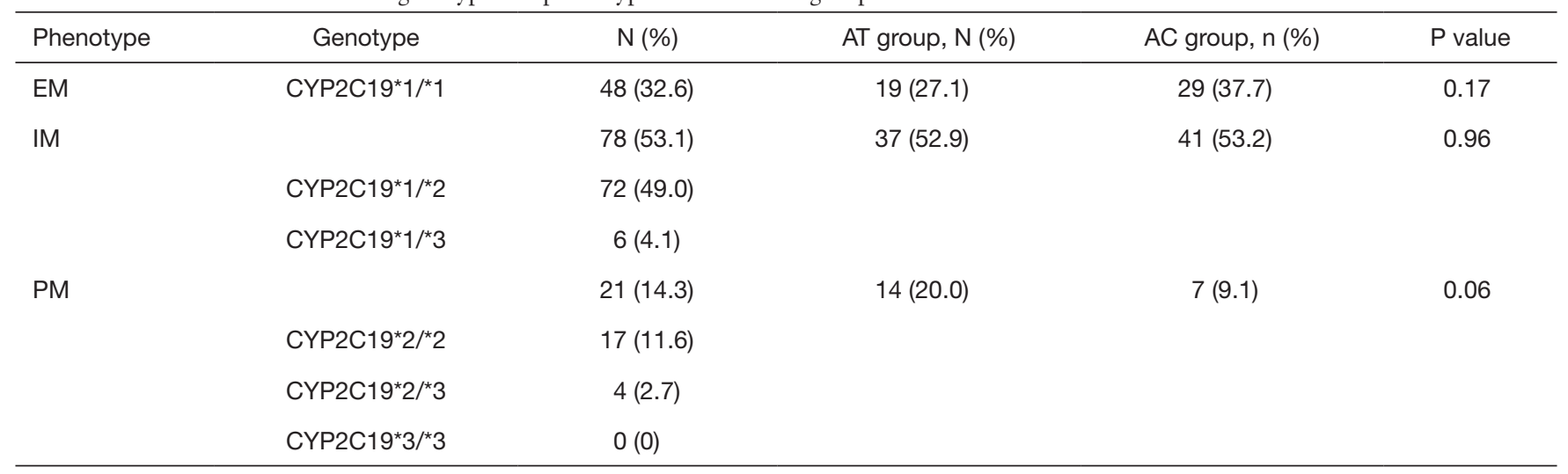

EM, extensive metabolizer, patients carrying normal function alleles (CYP2C19*1/*1); IM, intermediate metabolizer, patients carrying one loss-of-function allele (CYP2C19*1/*2, *1/*3); PM, poor metabolizer, patients carrying two loss-of-function alleles (CYP2C19*2/*2, ${ }^{*} 2 /{ }^{*} 3$, $\left.{ }^{*} 3 /{ }^{*} 3\right)$.

Table 7 Prevalence of graft occlusion in AT and AC groups with different CYP2C19 phenotype

\begin{tabular}{lccc}
\hline \multirow{2}{*}{$\begin{array}{l}\text { CYP2C19 } \\
\text { phenotype }\end{array}$} & \multicolumn{2}{c}{ SVG occluded, \% (n/total) } & \multirow{2}{*}{ P value } \\
\cline { 2 - 3 } & AT group & AC group & \\
\hline EM & $7.5(4 / 53)$ & $9.2(6 / 65)$ & 0.74 \\
IM & $9.3(7 / 75)$ & $8.6(8 / 93)$ & 0.87 \\
PM & $11.1(3 / 27)$ & $9.5(2 / 21)$ & 0.86 \\
P value & 0.86 & 0.99 & \\
\hline
\end{tabular}

EM, extensive metabolizer; IM, intermediate metabolizer; PM, poor metabolizer.

or aspirin+clopidogrel on SVG patency and incidence of cardiovascular events within one year after CABG. The results showed that both aspirin plus ticagrelor, or aspirin plus clopidogrel could maintain high graft patency in the early postoperative phase after CABG.

CYP2C19 loss-of-function has been associated with a high risk of major cardiovascular events in patients with coronary heart disease and those who received percutaneous intervention. However, a large meta-analysis suggested an association between the CYP2C19 genotype and clopidogrel responsiveness, but there was no significant association of genotype with cardiovascular events (11). Cayla et al. reported that the level of platelet reactivity is not always correlated with clinical outcomes in patients with ACS after coronary stenting (12). Moreover, Li et al. found that genetic variants related to clopidogrel metabolizing pathway had no effect one-year cardiovascular events in Chinese patients undergoing percutaneous coronary intervention (13). In our study, we also analyzed the association between the CYP2C19 genotype and DAPT responsiveness. We found no significant association of genotypes with graft patency during the $1^{\text {st }}$ year after elective CABG surgery. This could be due to our relatively small sample size. Further studies are needed to determine whether the significant benefits in graft patency exist in patients with different CYP2C19 genotypes.

The incidence of MACE was low in the two groups after 1-year follow-up. Moreover, there were few major bleeding episodes and there was no significant difference between the aspirin + ticagrelor group and the aspirin+clopidogrel group. Moreover, skin bleeding occurred more frequently in patients treated with combination therapy, which is consistent with previous studies of DAPT in a variety of settings $(8,9)$.

\section{Study limitation}

This was a single-center study that did not include the placebo control group. Additionally, although we tested variants of the CYP2C19 gene, still many other genes may be associated with clopidogrel response. In our study, there was no significant difference in graft patency among different CYP2C19 genotypes, probably due to the relatively small sample size. Consequently, a larger sample size might be warranted to reveal the effectiveness of different dual antiplatelet therapies on the clinical outcomes in patients with different CYP2C19 genotypes. 


\section{Conclusions}

Both aspirin plus ticagrelor, and aspirin plus clopidogrel can maintain a fairly high graft patency rate in the early phase after CABG surgery. Also, there were no significant differences in the incidence of MACE and major bleeding. CYP2C19 genotypes may have no obvious effect on graft patency during the 1 year after CABG surgery. Yet, a larger sample size study is required to confirm these findings.

\section{Acknowledgments}

Funding: The study was supported by the National Natural Science Foundation of China, Beijing, China (Grant No. 81870344).

\section{Footnote}

Reporting Checklist: The authors have completed the CONSORT reporting checklist. Available at http://dx.doi. org/10.21037/jtd-20-3407

Data Sharing Statement: Available at http://dx.doi. org/10.21037/jtd-20-3407

Peer Review File: Available at http://dx.doi.org/10.21037/jtd20-3407

Conflicts of Interest: All authors have completed the ICMJE uniform disclosure form (available at http://dx.doi. org/10.21037/jtd-20-3407). The authors have no conflicts of interest to declare.

Ethical Statement: The authors are accountable for all aspects of the work in ensuring that questions related to the accuracy or integrity of any part of the work are appropriately investigated and resolved. The study was conducted in accordance with the Declaration of Helsinki (as revised in 2013). The study was approved by the Institutional Review Board of Changhai Hospital (Number: CHCS052017). Informed consent was obtained from all patients.

Open Access Statement: This is an Open Access article distributed in accordance with the Creative Commons Attribution-NonCommercial-NoDerivs 4.0 International License (CC BY-NC-ND 4.0), which permits the noncommercial replication and distribution of the article with the strict proviso that no changes or edits are made and the original work is properly cited (including links to both the formal publication through the relevant DOI and the license). See: https://creativecommons.org/licenses/by-nc-nd/4.0/.

\section{References}

1. Alexander JH, Smith PK. Coronary-Artery Bypass Grafting. N Engl J Med 2016;374:1954-64.

2. Aldea GS, Bakaeen FG, Pal J, et al. The Society of Thoracic Surgeons Clinical Practice Guidelines on Arterial Conduits for Coronary Artery Bypass Grafting. Ann Thorac Surg 2016;101:801-9.

3. Goldman S, Zadina K, Moritz T, et al. Long-term patency of saphenous vein and left internal mammary artery grafts after coronary artery bypass surgery: results from a Department of Veterans Affairs Cooperative Study. J Am Coll Cardiol 2004;44:2149-56.

4. Serruys PW, Morice MC, Kappetein AP, et al. Percutaneous coronary intervention versus coronaryartery bypass grafting for severe coronary artery disease. $\mathrm{N}$ Engl J Med 2009;360:961-72. Erratum in: N Engl J Med 2013;368:584.

5. Gao G, Zheng Z, Pi Y, et al. Aspirin plus clopidogrel therapy increases early venous graft patency after coronary artery bypass surgery a single-center, randomized, controlled trial. J Am Coll Cardiol 2010;56:1639-43.

6. Gao C, Ren C, Li D, et al. Clopidogrel and aspirin versus clopidogrel alone on graft patency after coronary artery bypass grafting. Ann Thorac Surg 2009;88:59-62.

7. Wiviott SD, Antman EM. Clopidogrel resistance: a new chapter in a fast-moving story. Circulation 2004;109:3064-7.

8. Wallentin L, Becker RC, Budaj A, et al. Ticagrelor versus clopidogrel in patients with acute coronary syndromes. $\mathrm{N}$ Engl J Med 2009;361:1045-57.

9. Zhao Q, Zhu Y, Xu Z, et al. Effect of Ticagrelor Plus Aspirin, Ticagrelor Alone, or Aspirin Alone on Saphenous Vein Graft Patency 1 Year After Coronary Artery Bypass Grafting: A Randomized Clinical Trial. JAMA 2018;319:1677-86.

10. de Waha A, Sandner S, von Scheidt M, et al. A randomized, parallel group, double-blind study of ticagrelor compared with aspirin for prevention of vascular events in patients undergoing coronary artery bypass graft operation: Rationale and design of the Ticagrelor in CABG (TiCAB) trial: An Investigator-Initiated trial. Am 
Heart J 2016;179:69-76.

11. Holmes MV, Perel P, Shah T, et al. CYP2C19 genotype, clopidogrel metabolism, platelet function, and cardiovascular events: a systematic review and metaanalysis. JAMA 2011;306:2704-14.

12. Cayla G, Cuisset T, Silvain J, et al. Platelet function monitoring to adjust antiplatelet therapy in elderly patients stented for an acute coronary syndrome (ANTARCTIC):

Cite this article as: Tang Y, Fan X, Zhang B, Zhang J, Xue Q, $\mathrm{Xu} Z$, Han L. Aspirin plus ticagrelor or clopidogrel on graft patency one year after coronary bypass grafting: a single-center, randomized, controlled trial. J Thorac Dis 2021;13(3):1697-1705. doi: $10.21037 /$ jtd-20-3407 an open-label, blinded-endpoint, randomised controlled superiority trial. Lancet 2016;388:2015-22.

13. Li C, Zhang L, Wang H, et al. Gene variants in responsiveness to clopidogrel have no impact on clinical outcomes in Chinese patients undergoing percutaneous coronary intervention - A multicenter study. Int J Cardiol 2017;240:360-6. 